\title{
CABO VERDE E O ESPAC̣O DO ATLÂNTICO
}

\author{
Francisco Proença Garcia'
}

\section{Introdução}

Tradicionalmente quando olhamos para o Mapa-mundo temos presente a perspetiva cilíndrica em projeção Mercator, tendo como centro a região euro-atlântica; porém em Geopolítica sabemos que há diversas perspetivas da mesma realidade geográfica, e que o centro do Mapa é escolhido de acordo com a nossa noção de pertença a um determinado espaço, no fundo diferentes vivências históricas resultam em narrativas distintas de interesses e preferências normativas no comércio ou na segurança. Por exemplo, Nicholas Spykman (i969), na boa continuação da tradição de Thomas Mahan, considerava, na sua análise, o Continente Americano como central, demostrando como aquele detém uma posição geográfica favorável por estar voltado para os dois oceanos (Atlântico e Pacífico) o que lhe confere acesso às principais rotas comerciais do Mundo.

Hoje em Relações Internacionais e em Geopolítica é comum afirmar-se que houve uma transição da centralidade do poder político e económico da área euro-atlântica para a região da Ásia-Pacífico (Nye 20I4; Biscop et al. 20I5), porém na nossa abordagem vamos procurar mostrar que há uma reafirmação do Espaço do Atlântico sobretudo pela manutenção da importância geoeconómica da Europa comunitária, pelo novo dinamismo do link transatlântico mas sobretudo pelo interesse mostrado pelos poderes emergente e reemergentes no Atlântico Sul.

Cabo Verde acaba por ter um papel integrador de todo o Espaço do Atlântico devido à sua localização geográfica que potencia diversas pertenças. Integra a Comunidade Económica dos Estados da África Ocidental (CEDEAO), ao mesmo tempo possui uma Parceria Especial com a União Europeia (UE), faz parte da Comunidade de Países de Língua Portuguesa (CPLP),

I Professor Associado do Instituto de Estudos Políticos da Universidade Católica de Portugal. E-mail: franciscoproencagarcia@iep.lisboa.ucp.pt 
acolheu no seu território exercícios militares da Organização do Tratado do Atlântico Norte (OTAN), motivo suficiente para que a nossa curiosidade despertasse para um estudo geopolítico que relacione este arquipélago da costa africana com o Espaço do Atlântico.

\section{O Espaço do Atlântico}

O espaço do Atlântico de um ponto de vista geográfico engloba 86 milhões e 560 mil quilómetros quadrados, ou seja, 23,9\% da superfície da terra, abrangendo 30 países nas Américas, II na Europa e 24 em África (Correia 20Io), todos eles muito heterogéneos do ponto de vista politico, económico, social e cultural.

Esta imensa massa de água que liga o Pólo Norte à Antártida integra o Golfo do México, os Mares do Norte, Báltico, Caribe, Negro e Mediterrâneo, sendo possível considerar seis acessos: dois a norte (nordeste e noroeste), dois ao centro (Canal do Panamá e Estreito de Gibraltar) e dois ao sul (passagem Drake, Cabo da Boa Esperança), tendo a sua menor largura entre Natal (Brasil) e Freetown (Serra Leoa), definindo a linha que une estes dois pontos o equador geopolítico (Correia 2010).

O vasto espaço da Bacia do Atlântico é marcado por uma acentuada heterogeneidade mas ao mesmo tempo por crescente fatores de interdependência. Neste espaço encontramos uma comunidade de partilha de valores como a democracia e o comércio livre, que coexistem com tradições políticas, económicas, sociais e culturais diferenciadas nas diversas regiões e países (Grevi 20I6). No espaço do Atlântico encontramos diferentes níveis de desenvolvimento económico, de estabilidade institucional e de segurança, de ideologias, de clivagens religiosas, de organização familiar e da interpretação de valores como o dos Direitos Humanos.

Do ponto de vista geopolítico, o Atlântico Norte é mais homogéneo que os Atlântico médio ou Sul, caracterizando o designado Ocidente, comunidade de partilha de valores comuns.

\section{Regimes e Sistemas Políticos}

Ao analisarmos o mapa de um ponto de vista dos regimes e sistemas políticos verificamos que, no espaço do Atlântico, a maioria dos países são democracias, mais precisamente 62 democracias, I2 regimes considerados híbridos e 7 regimes autoritários (Gratius 2015); na Europa predominam os regimes democráticos (88\% dos países), sendo em menor valor percentual na 
América (apenas 2/3 dos países) e na África Atlântica apenas 20\% dos países são considerados democracias, 43\% autocracias e 37\% regimes híbridos (Gratius 2015) ${ }^{2}$.

Por outro lado também verificamos a existência de uma multiplicidade de unidades políticas em situação de fragilidade (fracas, falhadas ou colapsadas). Segundo o índice da Fund For Peace de 20I6, na Bacia do Atlântico são I2 as unidades políticas nesta situação, das quais II são em África e uma nas Caraíbas, o Haitỉ .

\section{Economia e recursos}

A interdependência económica e de investimentos na bacia do Atlântico têm sido crescentes desde o início do século. A sua intensidade é variável dado que há grande diversificação e diferenciação de economias. Entre a América do Norte e a Europa o comércio conta para 40\% do total que cruza o Atlântico, seguido do comércio UE-África (2I\%) e entre o Norte e Sul e América Central (I8\%) (Grevi 20I6).

A figura I representa o tráfego de navios nas diversas linhas de comunicação marítimas existentes, verificando-se uma maior densidade entre os dois pólos de desenvolvimento no Atlântico Norte, EUA e Europa, o que espelha a dinâmica comercial entre as duas margens, mas também podemos verificar um significativo tráfego marítimo Sul-Norte, sendo exemplo o expresso na figura, que retrata a densidade de tráfego entre o Brasil e o resto do mundo.

O tráfego marítimo nas Linhas de Comunicações (LCM) da costa brasileira contabiliza em média 359 navios mercantes diários (NM/d) e movimenta, anualmente, mais de 350 mil milhões de dólares; deste destacamos:

2 Sobre estes dados estatísticos podemos aprofundar em https://freedomhouse.org/report/ freedom-world/freedom-world-20i6.

3 Sobre estes dados devemos complementar em http://fsi.fundforpeace.org/. 


\section{Figura 1 - Domínios da circulação marítima}

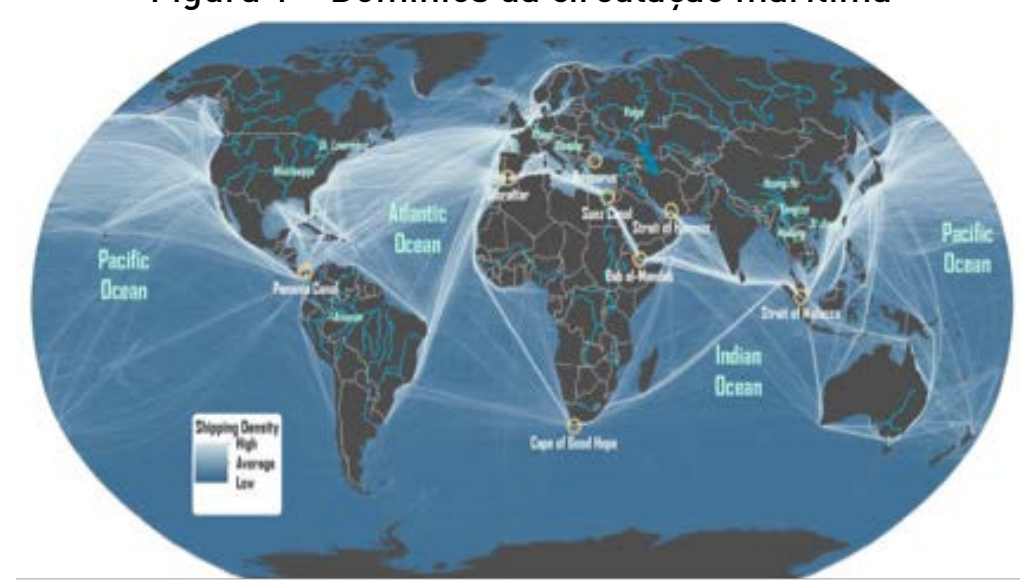

Fonte: European Union External Action 2014.

Figura 2 - Principais Linhas de Comunicação Marítimas (LCM) brasileiras que cortam o Atlântico Sul

- LCM com a Europa e o norte da África, com 2I5 NM/d;

- LCM com a América do Norte, Caribe e América do Sul setentrional, com $68 \mathrm{~N} \mathrm{M} / \mathrm{d}$

- LCM com a costa do Brasil, com $359 \mathrm{~N} \mathrm{M} / \mathrm{d}$;

- LCM com o Golfo da Guiné (centro da África), com $40 \mathrm{NM} / \mathrm{d}$;

- LCM com o Cone Sul e o Oceano Pacífico, com 77 NM/d;

- LCM com o sul da África, Oriente Médio e Ásia, por intermédio do Cabo da Boa Esperança (Rota do Cabo), com $65 \mathrm{~N} \mathrm{M} / \mathrm{d}$.

Fonte: Guerra 2011.

Apesar da expressão numérica significativa, o Atlântico Sul ainda é considerado um oceano de trânsito (Correia 20Io), e as principais rotas são ao longo da costa americana e africana. Devemos no entanto salientar que as principais rotas na direcção Sul-Norte cruzam o equador geopolítico e passam próximo a Cabo Verde, o que realça a importância deste e de outros arquipélagos da Macronésia (Açores, Canárias e Madeira).

O Espaço do Atlântico possui naquilo que podemos considerar o seu sistema de energia, uma grande parte das reservas fósseis não exploradas, incluindo $40 \%$ do petróleo, $20 \%$ do gás natural e $40 \%$ de carvão (BP 20I5), 
contando ainda com $67 \%$ das reservas tecnicamente recuperáveis de shale gas, $77 \%$ da capacidade instalada de energia solar, $64 \%$ da energia eólica e $59 \%$ da energia geotermal (Kraemer e Stefes 20I6).

As maiores reservas provadas de petróleo estão concentrados nas Américas e em parte da África Atlântica. No Brasil, por exemplo, as reservas de petróleo serão cerca de 46 mil milhões de barris, sendo possível, que a quantidade de petróleo alcance 70 a Ioo mil milhões de barris, além de grande volume de gás; na Venezuela estimam-se reservas de 80 mil milhões de barris (Hanson 2008).

Na região do Golfo da Guiné, a produção de petróleo representa cerca de $16 \%$ da produção mundial. Nesta instável região quase todos os campos petrolíferos estão localizados offshore, o que lhes garante alguma segurança da instabilidade que assola a área continental (Guedes 2013). Esta região inclui também a Bacia do Congo (segundo maior conjunto hídrico e florestal do mundo, depois da Amazónia), que cobre perto de dois milhões de quilómetros quadrados.

\section{Ameaças à Segurança}

No Atlântico também se manifestam diversas ameaças à segurança transnacional, sendo a mais gravosa a já referida debilidade do Estado. A debilidade do Estado pode e deve ser relacionada com as outras ameaças, pois, não possuindo poder ou controlo sobre a totalidade do seu território, os Estados ficam permeáveis a que dentro de si germinem e se desenvolvam as mais diversas formas de subversão (Garcia e Ferro 2013).

As Organizações Criminosas Transnacionais (OCT), com as verbas geradas, adquirem um nível de poder que compete com o dos Estados da região. Exprimem esse poder pela capacidade de criar diversas formas de instabilidade nos países onde operam, instabilidade de amplo espectro, da social a económica, da política à psicológica. Ao mesmo tempo, tentam conquistar indiretamente o poder político pela corrupção dos seus órgãos de soberania e dos seus funcionários, com a finalidade de intimidar o poder instituído, de forma a garantirem completa liberdade de ação nas suas atividades criminosas. Esta situação debilita ainda mais as fracas estruturas do Estado.

$\mathrm{Na}$ margem ocidental destacamos a violência criminal dos cartéis da droga e os milhares de mortes causadas pela sua atuação4 ${ }^{4}$ Países como a

4 Segundo o relatório Global Burden of Armed Violence de 20I5, publicado pela Geneva Declaration on Armed Violence and Development (2015), a América Central e do Sul, o Caribe e a 
Guatemala, as Honduras ou o México debatem-se para conter os elevados níveis de criminalidade violenta que afeta a autoridade do Estado (Grevi 20I6).

Na África Ocidental, uma região onde a maioria dos países se encontra entre os mais pobres do mundo, o tráfico de drogas é avaliado em centenas de milhões de dólares. As redes do tráfico de estupefacientes muitas vezes aproveitam as debilidades estruturais de países como a Guiné-Bissau e, com o beneplácito das elites dirigentes locais, acabaram por transformar a região num significativo centro de trânsito para a rota de distribuição da Europa5.

No relatório de 2014 da West Africa Commission on Drugs são apresentados dados relativos a 20 Io que revelam que nesse ano a maior parte do fluxo da cocaína oriunda da América Latina para a África Ocidental atravessou o arquipélago de Cabo Verde, de onde se dirigiu para a costa atlântica da região; desta análise podese também concluir que Cabo Verde é um dos principais pontos de trânsito entre a América Latina e o continente africano.

Apesar desta debilidade, Cabo Verde é considerado um caso de sucesso no continente africano em termos de desenvolvimento socioeconómico e de resiliência democrática, no fundo um pólo de estabilidade numa região volátil (Santos 20I4). Contudo, tem-se deparado com grandes dificuldades de financiamento sobretudo para a capacitação das suas forças e serviços de segurança. Esta vulnerabilidade está no entanto a ser colmatada com a ajuda internacional, sendo exemplo a inauguração em 20Io do Centro de Operações de Segurança Marítima (COSMAR) financiado pelos EUA.

Estas ameaças estão também relacionadas com a Conflitualidade Regional. São inúmeros os conflitos que assolam o espaço do Atlântico, e apenas para citar os mais relevantes: no Médio-Oriente temos o persistente problema israelo-palestiniano, a guerra civil Síria, e no Iraque, onde o Daesh se afirma como fenómeno subversivo à escala global; na Europa subsistem os problemas com a Rússia devido à situação na Ucrânia e na Geórgia; na Turquia além das convulsões internas, há a questão cipriota e novamente o problema do Kurdistão; na África do Norte permanece ainda a questão do estatuto do Sahara Ocidental, os conflitos na Líbia, no Mali e todas as manifestações de instabilidade e insegurança no Sahel; na África subsaariana destacamos toda a conflitualidade na Nigéria, quer em torno do Delta do Níger que com o Boko Haram; e não podemos deixar de referir o desastre humanitário na República Democrática do Congo onde a violência é endémica.

\footnotetext{
África do Sul lideram o número em mortes violentas.

5 Sobre este assunto podemos detalhar no relatório de 2014 da West Africa Commission on Drugs, onde se analisa a transformação da Guiné-Bissau num grande centro de distribuição de droga na Africa Ocidental: http://www.wacommissionondrugs.org/report.
} 
No espaço do Golfo da Guiné a pirataria constitui um exemplo claro de ameaça que pode colocar em causa a segurança económica e energética ocidental, pois aquela atividade criminosa impede a livre circulação de mercadorias (onde incluímos os hidrocarbonetos) nas linhas de comunicação marítima. A pirataria que se manifesta hoje no Golfo da Guiné contabiliza 600 ataques entre $2002 \mathrm{e}$ 20I2, afetando severamente a economia local e as atividades portuárias (Grevi 20I6). Em 20I2, o governo nigeriano estimava que 400.000 barris foram roubados diariamente, num custo total para o país de mil milhões de dólares mensais (Chatham House 2013).

Curioso notar que as OCT que operam na região, numa procura da conquista das populações, assumem algumas formas de responsabilidade social, substituindo-se ao Estados na construção de estradas, escolas e hospitais.

A tudo isto, em África acrescem as disparidades económicas e o exponencial crescimento demográfico. Este caldo de cultura na costa ocidental africana desperta fatores que acabam por fomentar a imigração irregular, forçando as populações a se deslocarem na procura de segurança e bem-estar.

O fator migratório (como elemento gerador de tensão e de alguma instabilidade), com o fluxo orientado predominantemente para os países do Ocidente, onde as novas comunidades que se instalam dificilmente são integradas nas sociedades locais, potencia o acréscimo de desencantados e de potenciais filiados e combatentes pela alternativa apresentada pela subversão global.

A imigração irregular, da qual as OCT se aproveitam, conduz à exploração da miséria humana. Vejam-se as situações dramáticas daqueles que procuram no eldorado europeu uma miséria doirada. Nas pateras que se dirigem para a margem norte do Mediterrâneo ou para as Canárias encontramos pessoas de todo o continente africano. Vêm sobretudo da África Ocidental, mas também do Sudão, Chade, Corno de África e mesmo da África Austral. Estes imigrantes na busca de segurança e bem-estar correm enormes riscos de vida. Muitos dos que não conseguem permanecem nos países de trânsito, que se transformam em destino. Chegam a ficar anos e a fasear a sua "operação de salto", o que lhes permite também terem diversos empregos informais durante a viagem, que lhes assegurará o pagar da etapa seguinte (IOM 2005).

O fenómeno migratório acompanha o povo caboverdiano, sendo inevitável falar neste fenómeno quando se fala da circunstância de Cabo Verde. Hoje, e resultante da emigração de há várias décadas sobretudo para a Europa, Estado Unidos, e África, o país conta com uma grande diáspora espalhada pelo mundo e estimada em cerca de 500 mil cidadãos (Cardoso 2006), ou seja, segundo os censos de 20Io, um número idêntico aos residentes no arquipélago ${ }^{6}$, o que

6 Segundo os dados do Censo 20ıo, a população cabo-verdiana era de 491.875 pessoas resi- 
potencia na política externa deste pequeno Estado a ideia de uma Nação global, e que serve de "vínculo na integração de Cabo Verde no plano internacional" (Madeira 20I6).

A mobilidade humana também potencia a transferência e partilha de conhecimentos e culturas, sendo que no caso de Cabo Verde, a sua diáspora pode ser considerada "uma comunidade transnacional porque os emigrantes funcionam como um elo de ligação de Cabo Verde com o resto do mundo. Eles sustentam uma relação social entre o país de acolhimento e o país de origem" (Cardoso 20II), fornecendo um importante contributo para a economia do país com as suas remessas monetárias, e ao mesmo tempo trazendo consigo novos modelos de negócio baseados na aprendizagem conseguida nos países de destino (Ridout e Goerg 20I6).

Com a crise económica e financeira e a instabilidade que assolou diversos países da região, Cabo Verde tornou-se também um país de destino de emigração, sobretudo devido às políticas de livre circulação para cidadãos da CEDEAO. Esta situação contribui muito para o debate intelectual, político e académico sobre a integração do país naquela comunidade (Madeira 20I3), o seu impacto económico, mas sobretudo o impacto cultural e identitário.

\section{Organizações Internacionais}

O Espaço do Atlântico contém em si regiões das mais integradas devido ao papel desempenhado por inúmeras Organizações Internacionais das mais diversas finalidades. Sem ser exaustivo: União Europeia (EU), União Africana (UA), Comunidade de Estado da África Ocidental (CEDEAO), Comunidade de Países de Língua Oficial Portuguesa (CPLP), Organização do Tratado do Atlântico Norte (OTAN) e Zona de Paz e Cooperação do Atlântico Sul (ZOPACAS). Estas Organizações acabam por constituir uma rede de plataformas de ligação dos países atlânticos e ao mesmo tempo "contribuiu para a diversificação das relações exteriores de muitos países do Sul global” (Ridout e Goerg 2016).

Neste nosso ensaio abordaremos apenas três Organizações Internacionais que possuem políticas e práticas relevantes para a segurança do Atlântico.

\section{União Europeia}

O Atlântico, que marca a fronteira ocidental da União Europeia (UE), é

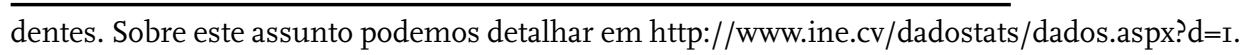


o grande espaço marítimo que define $2 / 3$ das fronteiras europeias, que integram quatro mares (Báltico, Norte, Mediterrâneo, Negro), vários arquipélagos, sendo alguns considerados regiões ultraperiféricas como a Reunião, Guiana, Martinica, Madeira e Guadalupe.

O mar tem um valor significativo na economia europeia, representando as regiões marítimas mais de $40 \%$ do PIB europeu. A UE também detém $40 \%$ da frota mundial de transporte marítimo. Um exemplo claro da importância que a UE atribui ao mar é a existência de seis agências que se preocupam com assuntos do mar (Frontex, EDA, EMSA, EEA, ACCP, ESA) (Correia 20I0), existindo ainda uma plêiade de várias políticas dispersas relacionadas com o mar, das quais destacamos o chamado Livro Azul (uma política marítima integrada para a União Europeia), o Plano de Ação para uma Estratégia Marítima na Região Atlântica, e a Estratégia de Segurança Marítima.

A execução da estratégia para o Atlântico definida pela Comissão Europeia exige um grande empenhamento quer das instituições comunitárias quer dos Estados-Membros e mesmo de entidades privadas. No Plano de Ação para uma Estratégia Marítima na Região Atlântica, a ser aplicado até 2020, são estabelecidas as prioridades em matéria de investigação, investimento e reforço de competências, que os Estados podem seguir de forma a fomentarem a "economia azul" na Região Atlântica de uma maneira sustentável e inclusiva nas zonas costeiras.

O Atlântico é vital para a segurança e o bem-estar da UE; para além das ameaças e riscos que se manifestam no domínio marítimo global, temos de ter em consideração que é através do mar que a UE processa 90\% do seu comércio externo e $40 \%$ do seu comércio interno (Rodrigues 20I4). A UE depende energeticamente das importações de petróleo $(88,4 \%)$ e de gás $(65,3 \%)$ oriundos sobretudo do Oriente Médio e da Eurásia (Eurostat 20I5), estando no entanto a diversificar as suas fontes de abastecimento, incluindo a proveniente do Atlântico, tendo crescido de I $8 \%$ para $23 \%$ entre 2006 e 2014 as importações provenientes de África; só em 2014 a Europa contava para $45 \%$ das exportações nigerianas e $20 \%$ das angolanas (Grevi 20I6), sendo assim imperioso garantir a liberdade de circulação no mar e a segurança do seu abastecimento.

Com a Estratégia de Segurança Marítima adotada em 20I4, pretende-se a defesa dos interesses marítimos que a Europa precisa salvaguardar na área marítima próxima (a dos espaços sob jurisdição dos Estados membros e a das suas aproximações pelo alto mar) bem como os interesses marítimos distantes (é o da segurança de rotas de navegação vitais, redes de transporte e de distribuição) que possam estar ameaçadas (Rodrigues 20I4).

Esta estratégia visa a fortalecer a resposta da União e integra cinco grandes áreas: ação externa; alerta marítimo, vigilância e partilha de informação; 
desenvolvimento de capacidades; gestão de risco, proteção de infraestruturas marítimas críticas; resposta a crises e ainda, inovação e investigação em segurança marítima, educação e treino.

Mas a maior ameaça "sistémica" na região não provém da atual competição entre as grandes potências. Do lado europeu, verificamos uma grave crise identitária da UE como grande Organização, sendo que consideramos que uma das maiores ameaças que enfrenta é interna, e passa muito pela renacionalização das suas Políticas Externa e Comum de Segurança e Defesa (PCSD).

Num momento em que a memória e a História se sobrepõem aos tratados, em que assistimos na UE a movimentos contrários de integração/ adesão e ao mesmo tempo de autoexclusão, devemos tirar as ilações necessárias sobre as consequências para a Segurança e Defesa europeia.

A UE adotou ainda uma estratégia conjunta com a UA, tendo por base os princípios de pertença e de responsabilidade conjunta, e ao mesmo tempo desenvolveu diversos mecanismos de diálogo e cooperação com organizações sub-regionais africanas. No âmbito da segurança há inúmeras iniciativas7, sobretudo para a região da África Ocidental e do Sahel, envolvendo a CEDEAO, para conter o tráfico ilícito, a pirataria e o terrorismo, tendo também tido papel de destaque no apoio à definição de uma arquitetura de paz e segurança africana (APSA), e projetado forças militares ao abrigo da PCSD no apoio à reforma do setor de segurança e defesa no Niger e no Mali.

Também os EUA e o Brasil, como veremos, têm exercícios navais na costa oeste africana envolvendo as marinhas da região, contribuindo para o treino e a capacitação institucional dessas marinhas.

Na margem atlântica de África a Comissão do Golfo da Guiné (CGG), que integra oito países da região, desempenha também um importante papel, sobretudo de coordenação e permuta de informação, que contribui para a segurança marítima regional.

\section{A OTAN}

Ao falar em segurança no Atlântico é mandatório abordar a Aliança Atlântica, que é uma Aliança regional com interesses globais, mas é também por excelência o garante do link transatlântico e continua a ser o mecanismo de segurança mais importante da Europa. Nenhuma outra organização tem

7 São exemplos o Plano de Ação da União Europeia para o Golfo da Guiné 2015-2020 e o Plano de Ação Regional para o Sahel 2015-2020. 
capacidade efetiva para planear e coordenar as diversas forças militares de todas as nações contribuintes.

A OTAN, na procura de garantia dos seus interesses, desde a sua criação assegura o controlo do mar, pelo menos no Atlântico Norte. Mas hoje, no atual ambiente de segurança marítimo, surgem ameaças não estatais e o reemergir da Rússia, pelo que a Aliança adotou em 2oII uma Estratégia Marítima que lhe permite contribuir para a Defesa e Segurança e a promoção dos seus valores. Esta estratégia materializa-se através das suas operações navais em quatro áreas: dissuasão e defesa coletiva; gestão de crises; segurança cooperativa e, segurança marítima. Quanto à segurança marítima em si, sempre dentro do estreito respeito da Lei, a OTAN pode vigiar e patrulhar em qualquer área definida pelo Conselho, e contribuir para a segurança energética, incluindo nisso as infraestruturas críticas e as linhas de comunicação marítimas (NATO 20II).

Cabo Verde também tem alguma importância estratégica para a OTAN. Recordamos que em 2005, o então Ministro dos Negócios Estrangeiros búlgaro, Salomon Passy, propôs formalmente a inclusão do Estado caboverdiano na Aliança Atlântica; e em junho de 2006, a OTAN levou a cabo os primeiros exercícios militares em África, o exercício Steadfast Jaguar (Guedes 20I2).

\section{A ZOPACAS}

No âmbito da Segurança e Defesa, Cabo Verde faz parte ainda de uma outra organização internacional com interesses no Atlântico Sul, a ZOPACAS.

A ZOPACAS, criada por iniciativa brasileira durante a Assembleia Geral das Nações Unidas em I986, integra 24 países. Esta Organização é mais um forum "para discutir a gestão do espaço do Atlântico Sul do que uma entidade militar ou política" (Ridout e Goerg 20I6) e tem como principal objetivo a promoção da cooperação regional e a manutenção da paz e segurança na região do Atlântico Sul. Além das iniciativas de cooperação, destacam-se as iniciativas de caráter político-diplomático, em especial no campo da proteção ambiental, do evitar a proliferação nuclear e de encontrar uma solução pacífica de conflitos entre seus integrantes.

A ZOPACAS não é uma organização de integração regional e apresentase mais como a estrutura que reúne todos os países dessa região, fomentando acordos de cooperação e interação no Atlântico Sul, do que um espaço para ação conjunta (Guerra 20II). A Organização surge revitalizada em 2013 após a VII Reunião Ministerial em Montevideu, num contexto em que o Brasil já havia descoberto as suas jazidas petrolíferas no pré-Sal do litoral de São Paulo; em que os Estados Unidos ressuscitaram a IV frota, quase 60 anos depois da sua 
dissolução em I950; bem como se verifica uma crescente presença da China na América do Sul.

A VIII Reunião Ministerial da ZOPACAS realizou-se na cidade do Mindelo, em Cabo Verde, entre 20 e 2I de maio de 2015 ,

tendo os participantes abordado os temas de cooperação na área da segurança marítima, da investigação oceanográfica, dos transportes marítimos, da cooperação universitária, e de tecnologias de informação e comunicação (Panapress 20I5).

Neste complexo contexto pela afirmação no espaço do Atlântico Sul, o Brasil aposta numa cooperação Sul-Sul, sendo central o progressivo reforço do papel da ZOPACAS, mas também de outros fóruns como o IBAS (India, Brasil e África do Sul). A cooperação marítima entre as Marinhas do Brasil, da Argentina, do Uruguai e da África do Sul tem sido uma realidade através de exercícios navais regulares, como o ATLASUR, mas também através do IBASMAR, que em 2008 e 20I0 exercitou conjuntamente forças navais do Fórum IBAS (Pereira 20I3).

Apesar destas ações de cooperação, não existe ainda uma articulação institucional das duas margens do Atlântico, onde circulam as mais diversas ameaças.

\section{Atlântico Sul}

O Atlântico continua a ser de grande interesse para os EUA, considerando que o país possui cinco comando combatentes diferentes responsáveis por áreas significativas do Atlântico (EUCOM, AFRICOM, CENTCOM, SOUTHCOM, NORTHCOM) e três frotas que projetam aí o seu poder naval: a segunda, a quarta e sexta frotas.

O Atlântico Sul despertou interesses mais recentes aos EUA, levando à criação do AFRICOM em 2008 e, de forma a atenuar o desvanecimento de sua hegemonia na região, à recriação da IV frota, como já referimos. A este interesse não serão estranhas as descobertas de reservas petrolíferas no offshore brasileiro e em vários países do Golfo da Guiné, que constituem alternativas de locais de fornecimento, muito mais estáveis do que o Oriente Médio e a Ásia Central, em grande e contínuas convulsões.

Com a diversidade de interesses navais por nós apresentada, a que podemos acrescer as ambições de Angola para deter uma capacidade oceânica (Correia 20I5), pergunstamos, afinal, quem controla o espaço do Atlântico do ponto de vista militar? Se ao Norte podemos considerar a OTAN ou ainda os EUA, a Sul, apesar das intenções brasileiras neste espaço oceânico, há um vasto 
conjunto de ilhas de soberania britânica: Ascenção, St Helena, Tristão da Cunha, Georgia e Sandwiche do Sul e Falkland, que formam um arco e que disputa essas intenções. Na posse destas ilhas, o Reino Unido reivindica ainda milhares de milhas quadradas no fundo do Oceano.

O reativar da IV frota sem qualquer consulta aos parceiros regionais não deixou de preocupar vários estados sul-atlânticos. Para o Brasil esta apresentase como uma ameaça às reservas de petróleo no mar, havendo autores como Moniz Bandeira (2008) que sugerem mesmo que uma "segunda Guerra Fria foi deflagrada e envolve a América do Sul, onde a penetração dos Estados Unidos constitui um fator de instabilidade e inquietação". O então Presidente do Brasil, Lula da Silva, afirmou que "quando os EUA estabelecem como prioridade reforçar a Quarta Frota do Atlântico, obviamente temos que nos preocupar. Eles dizem que é por uma questão humanitária mas nós não pedimos, ninguém pediu", o que levou o Presidente a apostar no reequipamento das Forças Armadas Brasileiras, nas indústrias de Defesa, mas também na proposta concreta à UNASUL de criação de um organismo de defesa para a região, o Conselho Sul-Americano de Defesa (Fonseca 20II).

Durante a Presidência de Lula da Silva, o Brasil aprovou em 2005 uma nova Política de Defesa Nacional e em 2008 a Estratégia de Defesa Nacional, onde se realçam as prioridades de Defesa para as Amazónias, Verde e Azul; mas também se posicionou como potência marítima no Atlântico Sul e como o principal dinamizador do regionalismo Sul-Americano e da cooperação Sul-Sul (Grevi 20ı6). Por exemplo, ao nível empresarial a aposta das empresas do setor de construção, mineiro e agro-industrial em África foi notório, nomeadamente em Angola; a sua rede diplomática mais do que duplicou desde 2002, contando atualmente com 38 representações oficiais, situações que contribuem para que o país represente $70 \%$ do comércio entre a América do Sul e África (Kotsopoulos 2014).

Podemos considerar que a cooperação Sul-Sul ganhou prioridade na agenda da política externa brasileira como forma de inserção internacional do país, constituindo hoje esta cooperação a essência da Agência Brasileira de Cooperação (Aguilar 20I3).

Uma das formas de cooperação é designada por "cooperação técnica", assente no apoio técnico, com o envio de especialistas em determinados setores de atuação para capacitar segmentos da população em áreas do conhecimento onde há carência de recursos técnicos (Aguilar 20I3).

A cooperação técnico-militar também desempenha um papel de destaque, tendo sido assinados acordos de cooperação, entre outros, com Cabo Verde em 1994, África do Sul em 2003, Guiné-Bissau em 2006, com a Namíbia em 2009, com a Nigéria, Senegal, Angola e Guiné Equatorial em 2010, para 
além dos exercícios navais entre as duas margens, e que já referimos. De realçar que ao nível da CPLP há os exercícios da série Felino e reuniões periódicas ao nível de Ministros da Defesa e de Chefes de Estado-Maior General.

O Brasil estabeleceu ainda cooperação estratégica em 2007 com a África do Sul e em 20 io com Angola e, a nível económico, o Mercosul (Mercado Comum do Sul) e a SADC (South African Development Community) concluíram em 2009 acordos de comércio preferenciais (Grevi 20I6).

No Atlântico Sul, podemos considerar ainda os diferentes interesses manifestados para a extensão da plataforma marítima das diversas Unidades Políticas que, no caso brasileiro, a designada Amazónia Azul corresponde grosso modo a um acréscimo de $50 \%$ da extensão territorial. Neste imenso espaço a Sul do Atlântico ainda podemos constatar diferentes interpretações quanto à delimitação fronteiriça entre as soberanias do Reino Unido e da Argentina, na região das Falkland/Malvinas. Posição distinta da encontrada na África Ocidental, onde seis ${ }^{8}$ países se juntaram para em conjunto solicitarem e verem reconhecidas as suas pretensões de extensão da plataforma continental.

Ao nível linguístico no Espaço do Atlântico manifestam-se diversas línguas francas (inglês, espanhol, português e francês) que facilitam a comunicação entre as diversas unidades políticas e as suas populações, promovem a socialização, facilitam os negócios e também são importantes fóruns de cooperação entre os países atlânticos`. No Atlântico Sul, o "Oceano Moreno” de Adriano Moreira (I993), é mais expressiva a presença da língua portuguesa no triângulo virtuoso Brasil-Cabo Verde-Angola.

Neste Espaço podemos considerar que está centrada a lusofonia, e que a CPLP pode ter um papel distintivo para a definição das políticas de desenvolvimento e de cooperação, mas também na definição de uma arquitetura estável de segurança.

\section{Cabo Verde no Espaço do Atlântico}

Quando falamos de Cabo Verde no contexto complexo, heterogéneo e dinâmico do Espaço do Atlântico, devemos lembrar o geopolítico Spykman (IAEM I982) , para quem "[a] geografia é o mais importante fator do poder nacional, porque o mais permanente", bem como que o valor geopolítico de um

8 Cabo Verde, Gâmbia, Guiné, Guiné-Bissau, Mauritânia, Senegal e Serra Leoa. Sobre este assunto devemos detalhar em http://www.un.org/Depts/los/clcs_new/submissions_files/ wa775_I4/wa7_es_en_sept2oI4.pdf.

9 No caso da língua portuguesa salientamos o importante estudo coordenado por Luís Reto (20I2), sobre o Potencial económico da Língua Portuguesa. 
determinado espaço é apenas conjuntural e depende da importância atribuída por outros estados (Correia 20I0).

Este pequeno país arquipelágico, situado a $500 \mathrm{~km}$ da costa ocidental africana, possui um território de $4033 \mathrm{~km} 2$ e conta com 500 mil habitantes. Estas características colocam-lhe enormes desafios no contexto político regional e internacional.

O primeiro grande desafio é o da afirmação e mesmo de sobrevivência. Neste desafio incluímos o da definição de pertença ou à Europa ou a África ${ }^{\mathrm{IO}}$. Este debate de décadas não é consensual em Cabo Verde.

Se formos apenas por uma abordagem geográfica, o país está mais próximo de África, mas a noção de pertença inclui outros fatores como a identidade e a cultura, também eles perenes em geopolítica. Cabral e a sua geração sempre foram defensores da africanidade, de uma maior integração no contexto regional africano (Cabral I978). Mas esta não é uma abordagem consensual, pois são diversos os que argumentam antes uma identidade europeia e integrada na civilização ocidental (Madeira 20I3).

Hoje este debate versa muito sobre uma maior integração na CEDEAO ou uma maior Parceria Especial com a UE, seus eventuais benefícios e desafios. Se a opção for pela CEDEAO, Cabo Verde será o único país insular a integrar uma comunidade de quinze Estados, detentora de um mercado de cerca de 250 milhões de consumidores (Monteiro 20I6). Mas o projeto de integração da Organização ainda não está consolidado e nos seus membros existem diversas dificuldades de ordem cultural, religiosa, política, bem como dificuldades com a livre circulação de pessoas, bens e capitais. Se a opção for pela maior integração regional africana, existirá sempre uma interação de fatores internos/externos, geopolíticos, económicos, demográficos, culturais e também religiosos, o que a tornará um processo complexo e moroso.

A outra opção, a Parceria Especial com a UE estabelecida em 2007 (então sob presidência portuguesa), "representa uma abordagem política que ultrapassa a mera relação de dador-benificiário" e não constitui uma alternativa aos Acordos de Cotonou. Esta parceria contempla um plano de ação assente em seis pilares: boa governação; segurança/estabilidade; integração regional; convergência técnica e normativa; sociedade do conhecimento; luta contra a pobreza e desenvolvimento (UE 2007).

Esta Parceria Especial ao contemplar no seu plano de ação a integração regional, permite que Cabo Verde estabeleça a ponte entre dois continentes (Madeira 2015). Por um lado ela valoriza uma aproximação às Regiões Ultraperiféricas e ao resto da União, e em simultâneo uma maior intensificação

Io Sobre este assunto podemos detalhar em Madeira 20I3. 
das relações regionais no âmbito da CEDEAO (UE 2007).

As opções a efetuar devem ser refletidas e avaliadas sobre as oportunidades e inconvenientes. Se passarem por uma maior integração, devem ser criados instrumentos que minimizem as suas vulnerabilidades e que combatam fenómenos que coloquem em perigo a soberania e a segurança do arquipélago (Madeira 20I5).

Num mundo cada vez mais globalizado, em nosso entender, Cabo Verde, para garantir a sua liberdade de ação, deve estabelecer alianças coerentes, mas sobretudo convenientes, premiando o multilateralismo, "procurando a mobilização de soluções político institucionais compreensíveis, capazes de contornar as vulnerabilidades de um Estado insular" (Monteiro 20ı6), de forma a reforçar as suas ligações com África, a Europa, o Brasil, a China, os EUA, a CPLP e o Atlântico Sul.

O segundo desafio prende-se com a segurança, onde se inclui o combate às mais diversas formas de crime organizado transnacional, de forma a permitir o desenvolvimento socioeconómico, este considerado como o terceiro desafio, que só será possível com uma boa governação e uma profunda consolidação institucional, cativadoras de Investimento Direto Estrangeiro, que virá exponenciar o desenvolvimento.

\section{Conclusões}

Da descrição efetuada podemos concluir que o Atlântico, espaço tão heterógeno, onde os desafios são complexos, multidimensionais e de uma escala global e onde não existe articulação institucional, não deixou de ser central para as relações internacionais, ou seja, que há uma reafirmação do Espaço do Atlântico quer do ponto de vista económico e dos recursos, quer do ponto de vista securitário.

Cabo Verde, neste Espaço, para continuar a ser diferenciador deve manter a vantagem da imagem de boa governação, de estabilidade politica e social e ir reduzindo as suas vulnerabilidades através de uma multiplicidade de parcerias, colocando ao mesmo tempo a sua soberania ao serviço da comunidade internacional.

\section{REFERÊNCIAS}

Aguilar, Sérgio. 2013. "Atlântico Sul: as relações do Brasil com os países africanos no campo da segurança e defesa". Austral: Revista Brasileira de Estraté- 
gia e Relações Internacionais 2 (4): 49-72.

Bandeira, Moniz. 2008. "A importância geopolítica da América do Sul na estratégia dos Estados Unidos". Revista Espaço Acadêmico 89.

Biscop, Sven, Jo Coelmont, Margriet Drent, and Dick Zandee. 20I5. European Strategy, European Defence, and the CSDP. The Hague: Clingendael Report.

BP. 2015. "Statistical Review of World Energy". British Petroleum. http:// www.bp.com/en/global/corporate/energy-economics/statistical-review-of-world-energy.html.

Cabral, Amilcar. 1978. Obras escolhidas. Porto: Seara Nova.

Cardoso, Pedro. 2006. Atlas da Lusofonia: Cabo Verde. Lisbon: Prefácio.

Cardoso, Sorraia. 2oII. "Importância da Diáspora na Política Externa de Cabo Verde”. MSc dissertation, Universidade do Minho.

Chatham House. 2013. Maritime Security in the Gulf of Guinea. Report of the conference held at Chatham House, London, 6 December 2012.

Correia, Armando. 20I0. O Mar no século XXI. Contributos pra uma análise estratégica aos desafios marítimos nacionais. Aveiro: FEDRAVE.

European Union External Action. 20I4. "The EU Maritime Security Strategy and Action Plan". December I6. http://eeas.europa.eu/archives/docs/ maritime_security/docs/maritime-security-information-toolkit_ en.pdf.

Eurostat. 20I5. "Database”. Eurostat. http://ec.europa.eu/eurostat/data/database.

Fonseca, Carmen. 20Iı. “O Brasil e a Segurança no Atlântico Sul”. Nação e Defesa 5 (г28): 77-9г.

Garcia, Proença, and Mónica Ferro. 20I3. "A Crise do Estado e a Segurança Internacional". Revista de Direito e Segurança I (I): 37-63.

Geneva Declaration on Armed Violence and Development. 2015. Global Burden of Armed Violence 2015: Every Body Counts. Geneva.

Gratius, Susanne. 2015. "Political, social and cultural trends in the Atlantic". Atlantic Future Scientific Paper 35.

Grevi, Giovanni. 20I6. "Power and Interdependence". In Atlantic Future. Shaping a new hemisphere for the 2Ist century; Africa, Europe and the Americas, I03-II5. Barcelona: CIDOB.

Guedes, Armando Marques. 20I2. "Da desregulação ao recentramento no Atlântico Sul, e a construção da 'Lusofonia". OBSERVARE - Universidade Autónoma de Lisboa 3 (I): I-37. 
Guerra, Wilson. 20ıı. “O Brasil e a Segurança do Atlântico Sul”. Nação e Defesa 5 (I28): 77-9I.

Hanson, Stephanie. 2008. "Energy Bottlenecks in South America". Council on Foreign Relations. Abril I6. https://www.cfr.org/backgrounder/energy-bottlenecks-south-america.

IAEM. I982. Origens e evolução histórica do pensamento geopolítico: Síntese histórica. ME 7I-००-००. Lisbon: Instituto de Altos Estudos Militares.

IOM. 2005. "World Migration". International Organization for Migrations. http://www.iom.int/jahia/Jahia/pid/8/wmr_annexes.pdf.

Kotsopoulos, John. 20I4. "The Atlantic as a new security area? Current engagements and prospects for security cooperation between Africa and its Atlantic counterparts". Atlantic Future Scientific Paper 20I4 (6).

Kraemer, Andreas, and Christof Stefes. 20I6. "The changing energy landscape in the Atlantic Space". In Atlantic Future Shaping a New Hemisphere for the 21st century: Africa, Europe and the Americas, 88-IO2. Barcelona: CIBOD.

Madeira, João Paulo. 20I3. "África versus Europa: Cabo Verde no Atlântico médio". Revista de Estudos Internacionais 4 (I): 46-59. . 2015. "Cape Verde: Geopolitics and projection of a small island state in West Africa". Austral: Brazilian Journal of Strategy \& International Relations 4 (8): 58-77.

. 2016. "Cabo Verde: De um Estado Inviável ao Pragmatismo da Política Externa”. Revista de Relaciones Internacionales, Estrategia y Seguridad II (2): 85-IOI.

Monteiro, Nataniel. 20I5. "África, a nova fronteira estratégica no desenvolvimento global: a geopolitica de Cabo Verde no contexto da CEDEAO”. Revista de Relaciones Internacionales, Estrategia y Seguridad II (2): 93-I09.

Moreira, Adriano. I993. "O Oceano Moreno". Ciência e Trópico 2I (2): 239-25I. NATO. 20II. “Alliance Maritime Strategy”. The North Atlantic Treaty Organization. www.nato.int/cps/eng/natohq/official_texts_756I5.htm.

Panapress. 2015. "Cabo Verde acolhe Encontro da Zona de Paz do Atlântico Sul". May I6. http://www.panapress.com/Cabo-Verde-acolhe-Encontro-daZona-de-Paz-do-Atlantico-Sul---3-630436760-4I-lang4-index.html.

Pereira, Analúcia Danilevicz. 2013. "O Atlântico Sul, a África Austral e a América do Sul: cooperação e desenvolvimento". Austral: Revista Brasileira de Estratégia e Relações Internacionais 2 (4): 33-48.

Reto, Luís. 20I2. Potencial económico da Língua Portuguesa. Lisbon: Texto. 
Ridout, Tim, and Madeleine Goerg. 20I6. "Institutions, interaction and idea flow in the Atlantic Space". In Atlantic Future Shaping a New Hemisphere for the 2Ist century: Africa, Europe and the Americas, 59-68. Barcelona: CIBOD.

Rodrigues, Alexandre Reis. 20I4. "Estratégia de segurança marítima europeia. Porquê e para quê??. Nação e Defesa 2014 (I37): I68-I76.

Spykman, Nicholas. I969. The Geography of the Peace. New York: Harcourt, Brace and Company.

UE. União Europeia. 2007. Communication from the Commission to the Council and the European Parliament on the future of relations between the European Union and the Republic of Cape Verde. Brussels, 24.I0.2007 COM (2007) 64I final

\section{RESUMO}

Neste artigo procura-se mostrar que a centralidade do Atlântico continua a ser uma realidade, sobretudo pela manutenção da importância geoeconómica da Europa comunitária, pelo novo dinamismo do link transatlântico mas sobretudo pelo interesse mostrado pelos poderes emergente e re-emergentes no Atlântico Sul. Neste contexto Cabo Verde desempenha um interessante papel integrador de todo o Espaço do Atlântico.

\section{PALAVRAS-CHAVE}

Geopolítica; Atlântico; Cabo Verde.

Recebido em 17 de dezembro de 2016. Aprovado em 22 de junho de 2017. 